\title{
Financial cost of elective day of surgery cancellations
}

\author{
Elina Turunen*1,2, Merja Miettinen ${ }^{3}$, Leena Setälä ${ }^{4}$, Katri Vehviläinen-Julkunen ${ }^{2,3}$ \\ ${ }^{1}$ Diaconia University of Applied Sciences, Finland \\ ${ }^{2}$ Department of Nursing Science, University of Eastern Finland, Finland \\ ${ }^{3}$ Kuopio University Hospital, Finland \\ ${ }^{4}$ Hospital District of Southwest Finland, Finland
}

Received: June 16, 2018

DOI: $10.5430 /$ jha.v7n6p30
Accepted: November 13, 2018 Online Published: November 19, 2018

URL: https://doi.org/10.5430/jha.v7n6p30

\begin{abstract}
Operative care is one of the major areas of healthcare services as over 310 million surgeries are conducted yearly. Surgery cancellations is a widely used indicator when evaluating the quality of preoperative care. Cancellations cause financial lost for organizations, however there is only limited research about the costs. The aim of this study was to evaluate the cost of elective day of surgery (DOS) cancellations in 13 operative specialties at a university hospital in Finland between September 1, 2015 and May 31, 2016 after a structured preoperative protocol was implemented to practice and a cancellation rate of $4.7 \%$ was recognized. Procedure prices conducted the data for the research and were collected from the hospital's invoicing system. Financial loss and savings of cancellations were calculated from the total cost of procedures. As a result the total cost of DOS cancellations during the nine-month time period was 953,374.27 euros and mean loss of a single cancelled operation was 2,459.91 euros. The total of material savings for the hospital were 106,917.33 euros. As a conclusion, DOS cancellations cause unnecessary wastage, and financial aspects should be followed and evaluated systematically by setting goals and providing continuing developments.
\end{abstract}

Key Words: Economics, Finance, Waste, Cost, Surgery cancellation, Operative care

\section{INTRODUCTION}

The hospital sector is the largest component of health care spending in the Organization for Economic Co-operation and Development (OECD) and European Union (EU) countries. ${ }^{[1]}$ Surgery is one of the major areas of healthcare services. Globally, approximately 312.9 million operations are conducted every year. ${ }^{[2]}$ According to study results of a cross-sectional and longitudinal study conducted in USA the mean cost of one minute of operation room (OR) time is approximately 36-37 US dollars. ${ }^{[3]}$ Day of surgery (DOS) cancellations are a recognized problem in perioperative care and one of the nursing-sensitive quality indicators in perioperative care. ${ }^{[4]}$ A single cancellation causes personal and economic harm for the patient ${ }^{[5]}$ and resource related waste for organizations. ${ }^{[6]}$

Cancellation occurrences vary widely across health care organizations; the highest rate may be more than 700 times higher than the lowest. ${ }^{[7]}$ Studies published since 2016 report variable elective DOS cancellation rates of $4.4 \%$ (tertiary care teaching hospital in Lebanon), ${ }^{[8]} 4.7 \%$ (university hospital in Finland) ${ }^{[9]} 8.8 \%$ (pediatric ambulatory surgery center in the US), ${ }^{[10]} 26 \%$ (regional hospital in Oman), ${ }^{[11]}$ and $44.5 \%$ (general hospital in South Africa). ${ }^{[12]}$ Similar to cancellation rates, costs of surgical procedures vary across countries and are related to the type of procedure. ${ }^{[7,13,14]}$

The development of surgical processes is encouraged as a

\footnotetext{
*Correspondence: Elina Turunen; Email: elturunen@gmail.com; Address: Department of Nursing Science, University of Eastern Finland, Yliopistonranta 1, P.O. Box 1627, FI-70211 Kuopio, Finland.
} 
way to reduce unnecessary costs. ${ }^{[1]}$ Practices for enhancing high-quality, safe and cost-effective perioperative processes have been implemented worldwide in recent years. Preoperative cost effectiveness requires optimization of the surgical process and patient specific management. ${ }^{[15]}$ A patientcentered approach to the reform of preoperative care has led to positive change, decreasing DOS cancellations and average length of stay and increasing patient volume, OR use, the number of patients admitted on the DOS, and patient satisfaction. ${ }^{[9,16-23,23-28,28]}$

"Cost" is defined as the amount of hospital expenditures for resources used to deliver care. ${ }^{[13]}$ Operational costs in the OR depend on start times, turnover times, cancellation rates, supplies, equipment, and staffing. ${ }^{[30]}$ The development and remodeling of surgical processes to achieve cost effectiveness have been encouraged. Researchers have been careful in measuring the economic impact of these changes, although evaluation based on cost is recommended. ${ }^{[16,26]}$

The aim of this study is to measure the financial cost of DOS cancellations. Data are drawn from a university hospital's 13 operative specialties after the implementation of an evidence based, structured preoperative protocol..$^{[9,31]}$

\section{Literature review}

A literature review of costs of DOS cancellations was conducted in PubMed and CINAHL in 2010-2017 using keywords such as "surgery", "operation", "cancellation", "cost", and "evaluation". Articles included in the literature review are presented in Table 1. A total of six academic journal articles reported on costs of cancellations. Four articles were published in the United States, ${ }^{[32-35]}$ one in Brazil, ${ }^{[36]}$ and one in South Africa. ${ }^{[12]}$ In addition, an editorial article published in the United States discussed OR time costs and suggested using an average cost of 15 to 20 US dollars per OR minute for a basic surgical procedure, excluding physician costs. $^{[13]}$

The earliest cost evaluation was based on data collected in $2004,{ }^{[36]}$ and the latest used data from 2014. ${ }^{[12,35]}$ Calculations of surgery cancellation costs were based on several different indicators: wasted OR time, ${ }^{[32,33]}$ hospital and physician data, such as the average surgeon fee for the planned procedure, including the average hospital facility fee per minute based on planned surgical time, ${ }^{[34]}$ an organization's annual statistics on what were considered unnecessary inpatient days, ${ }^{[12]}$ and nurse-led preoperative assessments. ${ }^{[35]}$ Costs of cancellations were measured after preparation of the operating room and during the operation, costs were divided into four parts: materials, fees, medication, and human resources. ${ }^{[36]}$

Published by Sciedu Press
The average cost of a cancelled operation in the US is approximately 5,000 to 8,000 US dollars. ${ }^{[33-35]}$ In South Africa, the cost is approximately 2,000 US dollars, ${ }^{[12]}$ and in Brazil, it is 30 US dollars. ${ }^{[36]}$ Wasted OR suite minutes cost 10 to 20 US dollars per minute on average in the US. ${ }^{[13,32]}$ Research on the financial cost of DOS cancellations is limited, and more evidence-based studies are needed to promote understanding of the costs of cancelled operations.

\section{Methods}

\subsection{Aims}

The aim of this study is to measure the financial cost of DOS cancellations using procedure prices for a university hospital's 13 operative specialties during a nine-month period.

\subsection{Research site}

The research was conducted at a university teaching hospital in Finland. The hospital is responsible for specialized medical care for nearly a million inhabitants and provides care in all surgical specialties. The hospital has 26 operating theaters where approximately 22,000 procedures are conducted yearly. OR staff work in elective surgery setting mainly Monday to Friday between 7:00 a.m.-3:30 p.m.

The hospital put a structured, evidence based preoperative protocol into clinical practice in all 13 operative specialties (gastrointestinal surgery; pediatrics; hand surgery; cardiac and thoracic surgery; urology; vascular surgery; neurosurgery; gynecology; ophthalmology; ear, nose, and throat surgery; dental surgery; orthopedics; and plastic surgery) between the years 2014 and 2015. In May 2015, all intraoperative care and recovery areas were gathered and moved to a single location while a new hospital building was being opened.

The new protocol was coordinated by preoperative nurses. Their main responsibility was to meet patients' needs individually, prepare patients for surgery, and cooperate with other professionals in the patients' care. ${ }^{[31]}$ The implementation of the new preoperative protocol led to an increase in the number of patients arriving at the hospital on the day of an operation and decreased the DOS cancellation rate significantly in cases where the "patient did not show up". The total DOS cancellation rate at the hospital was $4.7 \%{ }^{[9]}$

\subsection{Ethical approval}

The University Committee on Research Ethics evaluated the ethical aspects of this research and stated that the research was scientifically justified (25/2014). The university hospital granted permission to conduct the research (1/2015). 


\subsection{Data collection and analysis}

This was a retrospective cross-sectional cost evaluation study. for the period from September 1, 2015 to May 31, 2016 ${ }^{[9]}$ Data were collected from the hospital's invoicing system Costs of cancellations are reported in euros in terms of total with the hospital account manager's assistance. The data waste and savings.

were linked with DOS cancellation rates and reasons col- lected from an administrative database for surgical patients

Table 1. Research reporting costs of surgery cancellations (years 2007-2017)

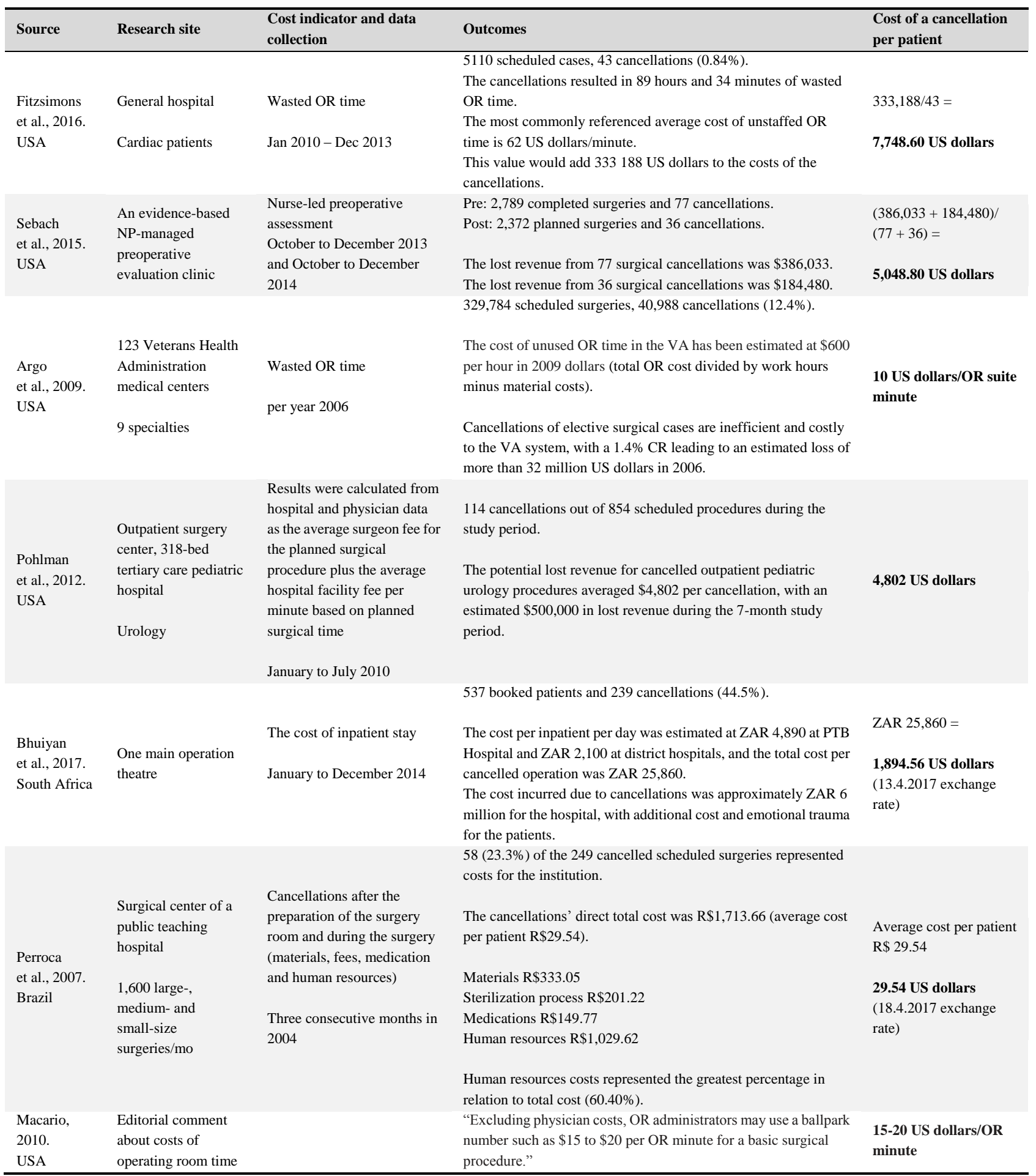




\section{Procedure prices}

Mean cost prices of operative procedures were collected from the hospital's invoicing system for the year 2016 in euros. The price of a procedure is calculated as mean costs of similar procedures during one year. There is no profit in the price as the hospital works as a non-profit institution. The price of a single operation consists of anesthesia resources, recovery room, implants, surgeon, medicine, environment (OR + OR staff), special equipment (e.g., a surgery robot) and specialty specific equipment. The cost of a cancellation was defined as resources that were reserved for the scheduled surgery for a specific patient. The model of calculation was that in case of a DOS cancellation, those resources could not be used for other purposes. DOS cancellation costs were calculated from the total cost of a procedure as follows:

DOS cancellation cost $=$ total cost of a procedure - saved unused products

Saved unused products $=$ implants + medicine + specialty specific equipment

DOS cancellation cost includes $=$ anesthesia resources \pm recovery room \pm surgeon \pm environment \pm special equipment

DOS cancellation costs were reported in 13 operative specialties in euros in means, total costs, and by cancellation reason during the nine-month study period. The invoicing system did not provide the procedure price in 33 cases. Missing data were replaced by specialty specific means of savings and costs.

\section{RESULTS}

Total costs of cancellations are presented in Table 2. The total cost of 542 elective surgery cancellations in 13 operative specialties was 953,374.27 euros in the nine-month study period, and the saving of material costs was $106,917.33$ euros. The mean loss from a single cancelled operation was 2,459.91 euros, and the mean saving was 174.47 euros. The highest mean losses were found in cardiac and thoracic $(4,539.93 €)$ and vascular surgery $(3,016.82 €)$, and the lowest were found in ophthalmology $(1,026.87 €)$ and urology $(1,315.58 €)$. However, because of the number of cancellations in ophthalmology, the total loss was one of the highest $(165,326.50 €)$ after orthopedics $(212,565.65 €)$ and neurosurgery $(165,416.39 €)$. Mean savings per cancelled operation were highest in gastrointestinal surgery (409.54€), cardiac and thoracic surgery (399.90 $€$ ), vascular surgery (338.63 €), and neurosurgery (313.72 €). Some specialties did not achieve any savings, or savings were minor; these included dental surgery $(0.19 €)$, plastic surgery (10.78 $€$ ), and pediatrics (18.36€).

Table 2. Costs and savings of DOS cancellations $(n=542)$ by operative specialties, September 1, 2015-May 31, 2016

\begin{tabular}{|c|c|c|c|c|c|c|c|c|c|}
\hline \multirow{2}{*}{ Medical specialty } & \multirow{2}{*}{$\begin{array}{l}\text { Cancellations } \\
\text { (n) }\end{array}$} & \multicolumn{2}{|c|}{ Missing data } & \multirow{2}{*}{$\begin{array}{l}\text { Cost per } \\
\text { cancellation } \\
\text { (mean } € \text { ) }\end{array}$} & \multirow{2}{*}{$\begin{array}{l}\text { Cost per } \\
\text { cancellation, range } \\
(€)\end{array}$} & \multirow{2}{*}{$\begin{array}{l}\text { Saving per } \\
\text { cancellation } \\
(\text { mean } €)\end{array}$} & \multirow{2}{*}{$\begin{array}{l}\text { Saving per } \\
\text { cancellation, } \\
\text { range } \\
(€)\end{array}$} & \multirow{2}{*}{$\begin{array}{l}\text { Total cost of } \\
\text { cancellations } \\
(€)\end{array}$} & \multirow{2}{*}{$\begin{array}{l}\text { Total saving of } \\
\text { cancellations } \\
(€)\end{array}$} \\
\hline & & (n) & $(\%)$ & & & & & & \\
\hline $\begin{array}{l}\text { Gastrointestinal } \\
\text { surgery }\end{array}$ & 24 & 2 & 7.7 & $1,945.52$ & $799.22-5,738.55$ & 409.54 & $130.30-1,003.79$ & $46,692.38$ & $9,828.96$ \\
\hline Pediatrics & 17 & 2 & 11.8 & $1,510.54$ & $929.52-2,888.52$ & 18.36 & $0-188.04$ & $25,679.12$ & 312.15 \\
\hline Hand surgery & 14 & 1 & 7.1 & $1,495.49$ & $998.75-2,374.01$ & 113.29 & $0-636.29$ & $20,936.91$ & $1,586.08$ \\
\hline Cardiac \& thoracic & 11 & 3 & 25 & $4,539.93$ & $1,532.25-6,679.74$ & 399.90 & $19.76-861.26$ & $50,890.33$ & $4,821.23$ \\
\hline Urology & 17 & - & - & $1,315.58$ & $822.23-1,724.01$ & 24.42 & $0-182.93$ & $22,364.90$ & 415.08 \\
\hline Vascular surgery & 20 & 3 & 15 & $3,016.82$ & $1,829.63-5,682.92$ & 338.63 & $49.48-588.42$ & $60,336.41$ & $6,772.51$ \\
\hline Neurosurgery & 73 & 2 & 2.7 & $2,265.98$ & $1,157.88-4,858.70$ & 313.72 & $0-914.43$ & $165,416.39$ & $22,901.64$ \\
\hline Gynecology & 28 & 7 & 25 & $1,519.92$ & $873.04-3,862.10$ & 140.07 & $0-448.72$ & $42,557.89$ & $3,921.91$ \\
\hline Ophthalmology & 161 & 7 & 4.3 & $1,026.87$ & $459.42-2,403.26$ & 188.17 & $0-920.44$ & $165,326.50$ & $30,296.06$ \\
\hline Ear, nose and throat & 69 & 1 & 1.4 & $1,343.10$ & $690.16-5,712.41$ & 74.87 & $0-460.27$ & $92,673.74$ & $5,165.75$ \\
\hline Dental surgery & 10 & 1 & 10 & $2,459.91$ & $626.80-3,064.51$ & 0.19 & $0-0.28$ & $24,599.11$ & 1.86 \\
\hline Orthopedics & 88 & 3 & 3.4 & $2,415.52$ & $1,206.18-5,363.11$ & 236.21 & $0-936.22$ & $212,565.65$ & $20,786.30$ \\
\hline Plastic surgery & 10 & 1 & 10 & $2,333.49$ & $1,238.27-8,274.29$ & 10.78 & $0-54.56$ & $23,334.94$ & 107.80 \\
\hline Total Hospital & 542 & 33 & 6.1 & $2,459.91$ & $459.42-8,274.29$ & 174.47 & $0-1,003.79$ & $953,374.27$ & $106,917.33$ \\
\hline
\end{tabular}


Table 3. Cost of DOS cancellations $(n=542)$ by reason and operative specialty, September 1, 2015-May 31, 2016

\begin{tabular}{|c|c|c|c|c|c|c|c|c|c|c|}
\hline \multirow[t]{3}{*}{$\begin{array}{l}\text { Medical } \\
\text { specialty }\end{array}$} & \multicolumn{2}{|c|}{ Patient did not show up } & \multicolumn{2}{|c|}{$\begin{array}{c}\text { Resource-related reasons } \\
\text { (no time for operation/rush, } \\
\text { equipment unavailable, a } \\
\text { surgeon unavailable, bed not } \\
\text { available) }\end{array}$} & \multicolumn{2}{|c|}{$\begin{array}{l}\text { Patient unfit for operation } \\
\text { (patient unsuitable for } \\
\text { operation or anesthesia) }\end{array}$} & \multicolumn{2}{|c|}{ No need for operation } & \multicolumn{2}{|c|}{$\begin{array}{c}\text { Other reasons } \\
\text { (non specific reasons or } \\
\text { administrative mistakes) }\end{array}$} \\
\hline & Cancellations & Cost & Cancellations & Cost & Cancellations & Cost & Cancellations & Cost & Cancellations & Cost \\
\hline & (n) & (€) & (n) & (€) & (n) & (€) & (n) & (€) & (n) & (€) \\
\hline $\begin{array}{l}\text { Gastrointestinal } \\
\text { surgery }\end{array}$ & - & 0 & 10 & $11,849.83$ & 11 & $31,668.03$ & 2 & $2,001.66$ & 1 & $1,172.85$ \\
\hline Pediatrics & 3 & $4,398.92$ & 1 & $1,504.01$ & 8 & $10,207.53$ & 4 & $6,695.11$ & 1 & $2,873.55$ \\
\hline Hand surgery & 2 & $3,884.87$ & - & 0 & 8 & $11,620.15$ & 4 & $5,431.90$ & - & 0 \\
\hline $\begin{array}{l}\text { Cardiac \& } \\
\text { thoracic }\end{array}$ & - & 0 & 2 & $8,588.80$ & 7 & $35,278.25$ & - & & 2 & $7,023.28$ \\
\hline Urology & - & 0 & 6 & $8,659.37$ & 4 & $4,565.76$ & 4 & $4,920.33$ & 3 & $4,219.44$ \\
\hline Vascular surgery & - & 0 & 8 & $20,762.93$ & 7 & $24,115.60$ & 3 & $8,489.47$ & 2 & $6,968.41$ \\
\hline Neurosurgery & - & & 36 & $79,018.96$ & 17 & $50,223.27$ & 12 & $22,291.46$ & 8 & $13,882.69$ \\
\hline Gynecology & 1 & $1,144.26$ & 7 & $10,316.46$ & 11 & $17,064.26$ & 6 & $10,080.27$ & 3 & $3,952.63$ \\
\hline Ophthalmology & 9 & 11,600 & 41 & $38,762.45$ & 74 & $67,681.15$ & 34 & $46,477.20$ & 3 & $4,853.22$ \\
\hline $\begin{array}{l}\text { Ear, nose and } \\
\text { throat }\end{array}$ & 3 & $3,312.49$ & 12 & $19,405.58$ & 26 & $32,368.02$ & 25 & $33,385.35$ & 3 & $4,202.31$ \\
\hline Dental surgery & 1 & $3,064.51$ & 3 & $7,621.58$ & 4 & $8,388.61$ & - & 0 & 2 & $5,524.42$ \\
\hline Orthopedics & 4 & $10,591.77$ & 48 & $118,193.52$ & 21 & $49,808.99$ & 7 & $173,44.65$ & 8 & $16,626.72$ \\
\hline Plastic surgery & 1 & $8,274.29$ & 1 & $1,333.77$ & 5 & $8,423.57$ & 3 & $5,303.31$ & - & 0 \\
\hline Total Hospital & 24 & $46,271.11$ & 175 & $326,017.26$ & 203 & $351,413.19$ & 104 & $162,420.71$ & 36 & $71,299.52$ \\
\hline
\end{tabular}

Regarding cancellation reasons (see Table 3), the most costly reason was patients' unsuitability for the planned operation $(n=203)$, causing a total loss of 351,413.19 euros. The largest shares of this cost were in ophthalmology $(67,681.15$ $€)$, neurosurgery $(50,223.27 €)$ and orthopedics $(49,808.99$ $€)$. Resource-related reasons $(\mathrm{n}=175)$ caused the loss of $326,017.26$ euros, including the largest losses in orthopedics $(118,193.52 €)$ and neurosurgery $(79,018.96 €)$. In 104 cases, patients were determined not to need the planned operation, leading to a total loss of 162,420.71 euros for the hospital; the highest shares in euros were found in ophthalmology $(46,477.20 €)$ and ear, nose and throat $(33,385.35 €)$. During the study period, there were 24 occasions when the patient did not show up at the hospital. These cancellations caused the loss of 46,271.11 euros, and the largest shares were in ophthalmology (11,600 €) and orthopedics (10,591.77 €). Other unspecified reasons led to a loss of 71,299.52 euros; the largest shares were in orthopedics $(16,626.72 €)$ and neurosurgery $(13,882.69 €)$.

\section{Discussion}

The aim of this study was to measure the financial cost of DOS cancellations in a university hospital's 13 operative specialties after the hospital implemented an evidence based structured preoperative protocol. ${ }^{[9,31]}$ According to the results, DOS cancellations caused a financial loss of nearly a million euros during the nine-month study period. To the best of our knowledge, this is the first academic study to measure the financial costs of surgery cancellations in Finland, and it supports previous estimates of the financial costs of elective surgery cancellations. ${ }^{[5,6]}$

Several factors, such as country and specialty, are recognized to affect the costs of cancellations. ${ }^{[13]}$ The mean cost of a cancellation was approximately 2,500 euros, which is approximately half the cost of a cancellation in the US. ${ }^{[33-35]}$ By specialty, the cost of a single DOS cancellation was highest in cardiac and thoracic and vascular surgery and lowest in ophthalmology. By reason for cancellation, a major loss was related to hospital resources and patients' suitability for the planned surgery. This finding suggests that a cancellation rate under $2 \%$ may be achieved.

DOS cancellations became less usual among many specialties but when total amount of cancellations was calculated in hospital-level, the result was distorted by the high frequency of cancellations in ophthalmic surgery. This was due to their process which was different from other specialties and did not include a preoperative visit to confirm the need of surgery. To use their OR resource effectively, they developed a system for rapid recruitment of additional patients for each day. During the study a new reporting system was created to support each department to further decrease their cancellations. Unfortunately, our study has no follow-up in this matter.

There are several limitations to this study, and the results are suggestive. As the data were collected from the hospital's invoicing system that is not originally designed for research 
purposes. However, the register may be seen as a reliable register including high quality data. It provides information that can be used for study purposes. To strengthen the analysis the assistance and participation of the hospital account manager was used. Financial causes of DOS cancellations are calculated as the mean costs of procedures over a year-long period. Procedure prices are limited in intraoperative care and do not include preoperative tests and care or postoperative care and hospitalization. In some cancellation cases a new patient may have been operated instead of a cancelled patient, but this was not considered in this study. Cancellation costs do not include any compensation paid to patients by the hospital. The reliability of this study might have been increased by using supportive data considering OR time used and minute-based costs, ${ }^{[13]}$ as in previous studies. ${ }^{[32-34]}$ However, reliable information about the use of OR time by operative specialty was not available for research purposes. The financial loss of DOS cancellations would best be measured in the standard manner using multiple supportive data sets.

The results of this study may be used to estimate the financial cost of DOS cancellations to organizations and to compare financial losses caused by elective surgery cancellations be- tween different health care providers. Financial costs of DOS cancellations are a valid outcome measurement when setting goals and evaluating outcomes in a perioperative setting.

\section{Conclusions}

As a conclusion, DOS cancellations cause unnecessary wastage for health care organizations. Financial aspects should be followed and evaluated systematically by setting goals and providing continuing developments for optimizing health care expenses.

\section{ACKNOWLEDGEMENTS}

We would like to acknowledge accounting manager Heini Koskenvuori, M.Sc. (Econ.), who helped with evaluating the usefulness of databases and disseminating funds, the North Savo Hospital District Ministry of Social Affairs and Health, and Kuopio University Hospital Research Foundation. We thank the Finnish Foundation for Nursing Education for making this research possible through funding.

\section{CONFlicts of InTEREST Disclosure}

The authors declare they have no conflicts of interest.

\section{REFERENCES}

[1] Lafortune G, Balestat G, Durand A. Comparing activities and performance of the hospital sector in Europe: how many surgical procedures performed as inpatient and day cases? 2012. Available from: https://www. oecd.org/health/Comparing-activities-a nd-performance-of-the-hospital-sector-in-Europe_In patient-and-day-cases-surgical-procedures.pdf

[2] Weiser TG, Haynes AB, Molina G, et al. Size and distribution of the global volume of surgery in 2012. Bulletin of the World Health Organization. 2016; 94(3): 201-209F. PMid: 26966331. https://doi.org/10.2471/BLT.15.159293

[3] Childers CP, Maggard-Gibbons M. Understanding costs of care in the operating room. JAMA Surgery. 2018; 153(4). PMid: 29490366. https://doi.org/10.1001/jamasurg. 2017.6233

[4] Wu Q, Huang LH, Xing MY, et al. Establishing nursing-sensitive quality indicators for the operating room: A cross-sectional Delphi survey conducted in China. Australian Critical Care. 2016; 30(1): 44-52. PMid: 27160417. https ://doi .org/10.1016/j . aucc. 2 016.04 .003

[5] Leslie RJ, Beiko D, van Vlymen J, et al. Day of surgery cancellation rates in urology: Identification of modifiable factors. Canadian Urological Association Journal. 2013; 7(5-6): 167-173. PMid: 23069699. https://doi.org/10.5489/cuaj.1345

[6] van Veen-Berkx E, Elkhuizen SG, van Logten S, et al. Enhancement opportunities in operating room utilization; with a statistical appendix. The Journal of Surgical Research. 2015; 194(1): 43-51. PMid: 25479906. https://doi.org/10.1016/j.jss. 2014.10.044

[7] McIntosh B, Cookson G, Jones S. Cancelled surgeries and payment by results in the English National Health Service. Journal of Health
Services Research \& Policy. 2012; 17(2): 79-86. PMid: 22315466. https://doi.org/10.1258/jhsrp.2011.011053

[8] Kaddoum R, Fadlallah R, Hitti E, et al. Causes of cancellations on the day of surgery at a Tertiary Teaching Hospital. BMC Health Services Research. 2016; 16: 259. PMid: 27412041. https ://doi.org/10 .1186/s12913-016-1475-6

[9] Turunen E, Miettinen M, Setälä L, et al. The impact of a structured preoperative protocol on day of surgery cancellations. Journal of Clinical Nursing. 2018; 27(1-2): 288-305. PMid: 28544205. https://doi.org/10.1111/jocn.13896

[10] Lee CM, Rodgers C, Oh AK, et al. Reducing Surgery Cancellations at a Pediatric Ambulatory Surgery Center. AORN Journal. 2017; 105(4): 384-391. PMid: 28336027. https://doi.org/10.1016/ j . aorn. 2017.01.011

[11] Appavu ST, Al-Shekaili SM, Al-Sharif AM, et al. The Burden of Surgical Cancellations and No-Shows: Quality management study from a large regional hospital in Oman. Sultan Qaboos University Medical Journal. 2016; 16(3): e298-302. PMid: 27606108. https://doi.org/10.18295/squmj.2016.16.03.006

[12] Bhuiyan MM, Mavhungu R, Machowski A. Provision of an emergency theatre in tertiary hospitals is cost-effective: Audit and cost of cancelled planned elective general surgical operations at Pietersburg Hospital, Limpopo Province, South Africa. South African Medical Journal. 2017; 107(3): 239-242. PMid: 28281430. https: //doi.org/10.7196/SAMJ.2017.v107i3.10687

[13] Macario A. What does one minute of operating room time cost? Journal of Clinical Anesthesia. 2010; 22(4): 233-236. PMid: 20522350. https://doi.org/10.1016/j.jclinane.2010.02.003

[14] Seim AR, Fagerhaug T, Ryen SM, et al. Causes of cancellations on the day of surgery at two major university hospitals. Surgi- 
cal Innovation. 2009; 16(2): 173-180. PMid: 19460816. https : //doi.org/10.1177/1553350609335035

[15] Snowden CP, Anderson H. Preoperative optimization: rationale and process: is it economic sense? Current Opinion in Anesthesiology. 2012; 25(2): 210-216. PMid: 22157198. https ://doi.org/10.1 $097 / \mathrm{ACO} .0 \mathrm{~b} 013 \mathrm{e} 32834 \mathrm{ef} 903$

[16] Boudreau SA, Gibson MJ. Surgical Cancellations: A Review of Elective Surgery Cancellations in a Tertiary Care Pediatric Institution Journal of PeriAnesthesia Nursing. 2011; 26(5): 315-322. PMid: 21939884. https://doi.org/10.1016/j.jopan.2011.05.00 3

[17] Deng X, Wang Y, Zhu T, et al. Short message service (SMS) can enhance compliance and reduce cancellations in a sedation gastrointestinal endoscopy center: a prospective randomized controlled trial. Journal of Medical System. 2015; 39(1): 169. PMid: 25476268. https://doi .org/10.1007/s10916-014-0169-z

[18] Gheysari E, Yousefi H, Soleymani H, et al. Effect of six sigma program on the number of surgeries cancellation. Iranian Journal of Nursing and Midwifery Research. 2016; 21(2): 191-196. PMid: 27095994. https://doi.org/10.4103/1735-9066.178247

[19] Haufler K, Harrington M. Using Nurse-to-Patient Telephone Calls to Reduce Day-of-Surgery Cancellations. AORN Journal. 2011; 94(1): 19-26. PMid: 21722768. https://doi .org/10.1016/j. aorn.2 010.12 .024

[20] Higson J, Finlay T. Pre-assessment for children scheduled for day surgery. Nursing Management. 2010; 17(8): 32-38. PMid: 21229870. https://doi.org/10.7748/nm2010.12.17.8.32.c8146

[21] Hovlid E, von Plessen C, Haug K, et al. Patient experiences with interventions to reduce surgery cancellations: a qualitative study. BMC Surgery. 2013; 13: 30. PMid: 23924167. https://doi.org/ 10.1186/1471-2482-13-30

[22] Hovlid E, Bukve O, Haug K, et al. A new pathway for elective surgery to reduce cancellation rates. BMC Health Services Research. 2012 12: 154. PMid: 22686475. https://doi .org/10.1186/1472-6 963-12-154

[23] Lee A, Kerridge RK, Chui PT, et al. Perioperative Systems as a quality model of perioperative medicine and surgical care. Health Policy. 2011; 102(2-3): 214-222. PMid: 21680044. https ://doi.org/10 $.1016 / j$. healthpol.2011.05.009

[24] Lozada MJ, Nguyen JT, Abouleish A, et al. Patient preference for the pre-anesthesia evaluation: Telephone versus in-office assessment Journal of Clinical Anesthesia. 2016; 31: 145-148. PMid: 27185698. https://doi.org/10.1016/j.jclinane.2015.12.040

[25] McKendrick DR, Cumming GP, Lee AJ. A 5-year observational study of cancellations in the operating room: Does the introduction of preoperative preparation have an impact? Saudi Journal of Anaesthesia. 2014; 8(Suppl 1): S8-S14. PMid: 25538529. https : //doi.org/10.4103/1658-354X.144053
[26] Olson RP, Dhakal IB. Day of surgery cancellation rate after preoperative telephone nurse screening or comprehensive optimization visit. Perioperative Medicine. 2015; 4: 12. PMid: 26664719. https://doi.org/10.1186/s13741-015-0022-z

[27] Ortiga B, Capdevila C, Salazar A, et al. Effectiveness of a Surgery Admission Unit for patients undergoing major elective surgery in a tertiary university hospital. BMC Health Services Research. 2010; 10: 23. PMid: 20096114. https://doi.org/10.1186/1472-6 963-10-23

[28] Pereira L, Figueiredo-Braga M, Carvalho IP. Preoperative anxiety in ambulatory surgery: The impact of an empathic patient-centered approach on psychological and clinical outcomes. Patient Education and Counseling. 2016; 99(5): 733-738. PMid: 26654958. https://doi.org/10.1016/j.pec.2015.11.016

[29] Siragusa L, Thiessen L, Grabowski D, et al. Building a Better Preoperative Assessment Clinic. Journal of PeriAnesthesia Nursing. 2011; 26(4): 252-261. PMid: 21803273. https://doi.org/10.1016/j . jopan.2011.05.008

[30] Vassell P. Improving OR Efficiency. AORN Journal. 2016; 104(2): 121-132. PMid: 27472972. https://doi .org/10.1016/j . aorn .2016 .06 .006

[31] Turunen E, Miettinen M, Setälä L, et al. An integrative review of a preoperative nursing care structure. Journal of Clinical Nursing. 2017; 26(7-8): 915-930. PMid: 27325370. https ://doi.org/10 $.1111 /$ jocn. 13448

[32] Argo JL, Vick CC, Graham LA, et al. Elective surgical case cancellation in the Veterans Health Administration system: identifying areas for improvement. American Journal of Surgery. 2009; 198(5): 600-606. PMid: 19887185. https ://doi.org/10.1016/j.amjs urg. 2009.07.005

[33] Fitzsimons MG, Dilley JD, Moser C, et al. Analysis of 43 Intraoperative Cardiac Surgery Case Cancellations. Journal of Cardiothoracic and Vascular Anesthesia. 2016; 30(1): 19-22. PMid: 26597766. https://doi.org/10.1053/j.jvca.2015.08.007

[34] Pohlman GD, Staulcup SJ, Masterson RM, et al. Contributing factors for cancellations of outpatient pediatric urology procedures: single center experience. The Journal of Urology. 2012; 188(4 Suppl): 16341638. PMid: 22910272. https://doi.org/10.1016/j.juro.2 012.03 .111

[35] Sebach AM, Rockelli LA, Reddish W, et al. Development of a Nurse Practitioner-Managed Preoperative Evaluation Clinic Within a Multispecialty Orthopedic Practice. Journal for Nurse Practitioners. 2015; 11(9): 869-827. https://doi.org/10.1016/j .nurpra.2 015.06 .006

[36] Perroca MG, Jerico Mde C, Facundin SD. Surgery cancelling at a teaching hospital: implications for cost management. Revista Latino-Americana De Enfermagem. 2007; 15(5): 1018-1024. PMid: 18157457. https://doi.org/10.1590/S0104-1169200 7000500021 